\title{
Harold L. Dibble, Shannon J.P. McPherron, Paul Goldberg and Dennis M. Sandgathe (eds): The middle Paleolithic site of Pech de l'Azé IV, 2018
}

\author{
Rachel Cajigas $^{1}$
}

Accepted: 21 February 2019 / Published online: 26 February 2019

(c) Springer-Verlag GmbH Germany, part of Springer Nature 2019

The Middle Paleolithic Site of Pech De L'Aze is a comprehensive final report on the archaeological excavations conducted at the Pech de l'Azé IV site in the Perigord region of southwest France. This collapsed cave site has a long history of hominin use during the early Late Pleistocene ( 99-45 ka) and throughout various climate and ecological changes.

The book is composed of seven chapters that review the unpublished excavations conducted by François Bordes in the 1970s, recent analysis of this archaeological material, and additional excavations in the early 2000s by Dibble and McPherron (editors). These excavations used high-resolution mapping techniques, petrographic analysis of undisturbed soils, analysis of animal bones and lithic artifacts, and various dating techniques to create a long-term chronological framework spanning approximately 60,000 years. This chronology speaks to changes in site use and Neanderthal behavior, changes in the climate and ecology, and the morphology of the cave architecture.
Due to some of the results from this research having been published elsewhere, the book also aims to provide the metadata necessary for future scholars to re-analyze these artifact assemblages and the data generated. It thoroughly discusses the various methods of artifact and dating analyses and is illustrated with numerous high-quality color photographs, detailed tables, and hand-drawn illustrations of the artifacts. This effort is an excellent example of responsible curation and discussion of the processes of archaeological analysis and excavations that often are not published.

The book is highly recommended to those interested in the Middle Paleolithic, as well as archaeologists interested in the use of various high-resolution datasets over long stratigraphic sequences.

Publisher's Note Springer Nature remains neutral with regard to jurisdictional claims in published maps and institutional affiliations.
Rachel Cajigas

cajigas@email.arizona.edu

1 Department of Geosciences, University of Arizona, 1040 E. 4th St., Tucson 87521, USA 